\title{
Noticias sobre las crecidas del Guadalquivir en Sevilla en la primera década del siglo XVII. Edición de una relación en verso de la «avenida de san Benito» en 1608*
}

\author{
Rosario Consuelo Gonzalo García \\ Universidad de Valladolid \\ gonzaloc@paa.uva.es
}

Recepción: 12/05/2019, Aceptación: 16/07/2019, Publicación: 04/12/2019

\begin{abstract}
Resumen
El propósito de este artículo es dar noticia bibliográfica de las relaciones de sucesos que informan sobre las inundaciones causadas por el río Guadalquivir en Sevilla en la primera década del siglo xvir. Estas piezas han aparecido en los últimos años en distintas bibliotecas públicas y privadas. También se edita el texto de la relación compuesta por Diego de Brizuela Corcuera, por ser el primer testimonio poético conocido de la «avenida de san Benito» en 1608.

Palabras clave

relaciones de sucesos; duque de T'Serclaes de Tilly; pliegos poéticos del siglo Xvir; riadas del Guadalquivir; clima; meteorología
\end{abstract}

\begin{abstract}
News Reports on the Floods Produced in Seville by the River Guadalquivir in the First Decade of the Seventeenth Century. With the Critical Edition of a Report in Verse of the 'San Benito Flood' of 1608 This article offers bibliographical details of the printed news letters (relaciones de sucesos) that report the floods caused by the river Guadalquivir in Seville in the first decade of the

* Esta investigación se ha realizado en el marco del proyecto Biblioteca Digital Siglo de Oro V (código FFI2015-65799-P), financiado por el Ministerio de Economía y Competitividad del Gobierno de Espańa y por el Fondo Europeo de Desarrollo Regional (FEDER). Agradezco a los propietarios del legado del duque de T'Serclaes y a los responsables de las bibliotecas con las que he contactado el haberme concedido permiso para reproducir las figuras que se enumeran en este trabajo. Igualmente, quiero expresar mi gratitud a Emilio Pascual por sus valiosos consejos, imprescindibles en la edición de la relación que acompaña al estudio.
\end{abstract}


seventeenth century. These publications have been identified only in the past few years in various public and private libraries. Furthermore, it offers an edition of the news letter written by Diego de Brizuela Corcuera, the earliest known news letter in verse on the 'San Benito flood' of 1608 .

\section{Keywords}

relaciones de sucesos; printed news letters; Duque of T'Serclaes de Tilly; 17th-century pamphlets in verse; Guadalquivir floods; climate; meteorology

La historia de Sevilla va ineludiblemente unida a la de su río. El Guadalquivir fue el principal motor de riqueza y desarrollo de la ciudad hispalense, pero también se convirtió en la peor pesadilla de sus habitantes durante más de tres centurias. Cada vez que su caudal se desbordaba a causa de las tormentas y las lluvias torrenciales, la ciudad se anegaba sin remedio y solo se respiraba calamidad, destrucción y ruina. Desde el siglo xv hasta finales del xviI, se computan más de cuarenta riadas de variable duración, intensidad y fama, de las que hemos tenido noticia gracias, fundamentalmente, a los testimonios de historiadores, cronistas, eruditos locales y relacioneros que se hicieron eco de las sucesivas desgracias que iba ocasionando el río a su paso por Sevilla. ${ }^{1}$

En la primera década del seiscientos, el Guadalquivir se salió de su cauce al menos en dos grandes ocasiones —en diciembre de 1603 y en marzo de 1608 - , provocando un gran pánico, cuantiosas pérdidas personales y materiales y mucha incertidumbre. Como enseguida veremos, los trágicos sucesos de estas dos inundaciones se difundieron dentro y fuera de España por medio de la literatura de cordel, tal como lo ponen de manifiesto los curiosos opúsculos que

1. Para un análisis detallado de las causas y consecuencias de estas crecidas fluviales, remito a los estudios de González de Caldas (1985: 54-60), Carmona (2000: 85-120) y Peña Díaz (2017: 47-55). 
han ido aflorando en los últimos años en distintas bibliotecas públicas y privadas. En el presente trabajo, además de dar noticia bibliográfica de las relaciones que se publicaron sobre estos desastres naturales, ofrezco la edición del primer testimonio poético conocido del diluvio de 1608.

\section{La avenida de santo Tomé en 1603}

A 20 de diciembre de 1603, una intensa y devastadora riada conmocionó a la sociedad hispalense y se convirtió de inmediato en un "caso noticioso", integrándose en los Sucesos de Ariño (1873: 115-116), en las Relaciones de Cabrera de Córdoba (1857: 205-206) y en los Anales de Ortiz de Zúñiga (1677: 602-603). Conocida como la «avenida de santo Tomé» por haber ocurrido en la víspera de su festividad, de ella nos proporcionó Palomo abundantes detalles en su Historia critica de las riadas (1878, I: 211-220). Entre los impresos coetáneos que este historiógrafo pudo consultar a la hora de documentar el suceso, se encuentran dos curiosas relaciones en verso de disímil factura literaria. ${ }^{2}$

La primera relación salió de la pluma de un poeta ocasional, el sevillano Tomás de Mesa, que adoptó el verso de romance para narrar el Andeluvio (sic) y ruina que hizo el río Guadalquivir en la ciudad de Sevilla y Triana y otros pueblos comarcanos, en veinte de diciembre deste año de mil y seiscientos y tres. Donde se da cuenta del mucho mal que hizo, derribando casas, ahogando gentes, echando a perder mucha suma de mercaderias, hundiendo navios de trigo, y otras cosas... Esta relación se imprimió en los últimos días de diciembre de 1603 en Sevilla, en casa de Fernando de Lara, en formato $4^{\circ}$, de 4 hojas, y de ella tuvieron un ejemplar tanto el bibliófilo inglés Henry Huth como el marqués de Jerez de los Caballeros. ${ }^{3}$ Descrita sucesivamente por Gallardo (1888), Hazañas (1892), Palau (1956), Simón Díaz (1984) y Domínguez Guzmán (1992), de esta edición solamente se localiza hoy un ejemplar en la Biblioteca Nacional de España, con signatura VE-1428(1), el cual fue adquirido al librero Guillermo Blázquez Barbero en 1998 (vid. figura 1). ${ }^{4}$

2. Según indica el propio Palomo (1878, I: 213), pudo consultarlas gracias a la bondad de José Sancho Rayón, que le franqueó la consulta a estas dos joyas bibliográficas de su colección privada.

3. Este pliego aparece descrito en los dos catálogos de la biblioteca de Huth (1880, III: 960, y 1914, IV, n.o 4946). También consta en el catálogo de la biblioteca del marqués de Jerez (Rodríguez Moñino 1966: 100), pero no figura en Penney (1965), ya que el ejemplar no llegó a la Hispanic Society. Esta ausencia me la ha confirmado amablemente Jonh O'Neill en un correo electrónico de 14/10/2018.

4. Vid. noticia bibliográfica 1 al final de este artículo. Aunque desconozco la procedencia de este ejemplar, sospecho que podría haber pertenecido a la biblioteca del duque de T'Serclaes, a juzgar por su carpetilla de protección, parecida a otras que he podido examinar. En este sentido, hay que recordar que Guillermo Blázquez vendió en 1998 a la Nacional varios impresos procedentes de T'Serclaes (vid. Gonzalo García 2018: 199 y 225). 


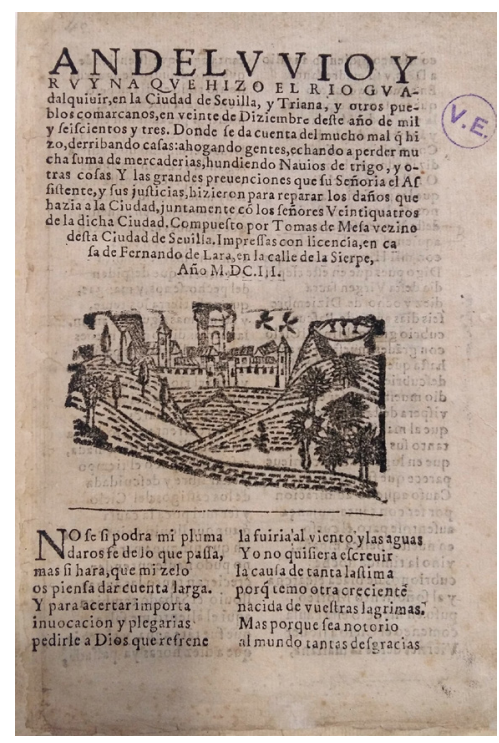

Figura 1

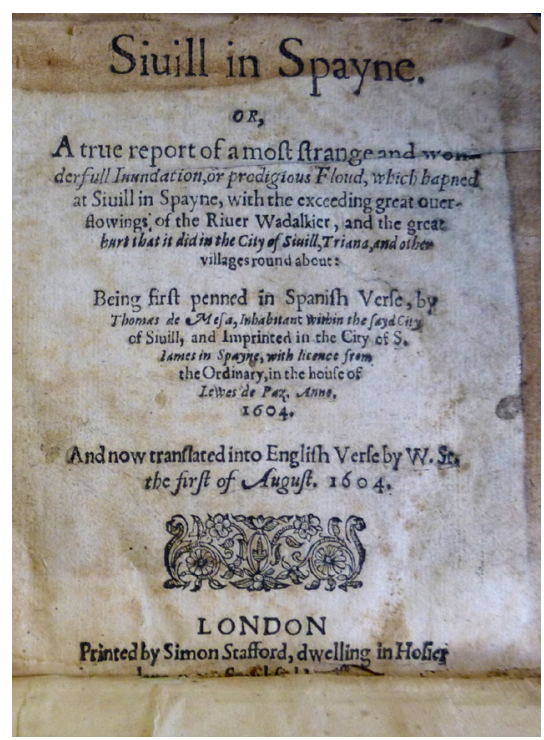

Figura 2

Hace poco, además, he podido averiguar que esta relación tuvo otros dos focos importantes de difusión, lo que, sin duda, acredita su éxito editorial dentro y fuera de la península Ibérica. ${ }^{5}$ Tras la localización de un ejemplar incompleto, con signatura F.8.38(2), que sirvió como hoja de guarda en la encuadernación de otra obra conservada en la biblioteca Chetham de Manchester, ${ }^{6}$ puedo confirmar que el impresor Simon Stafford publicó en Londres una traducción al inglés del relato de Mesa, realizada por un misterioso W. St. el primero de agosto de 1604, para lo cual — según se especifica en el título- se sirvió de otra edición previa en castellano, impresa por Luis de Paz en Santiago de Compostela en ese mismo año: Sivill in Spaine. Or, A true report of a most strange and wonderfull inundation, or prodigious floud, which hapned at Sivill in Spaine, with the exceeding great overflowings of the river Wadalkier, and the great hurt that it did in the city of Sivill, Triana, and other

5. El arranque de la prensa preperiódica a escala europea ha sido investigado por Ettinghausen en How the Press Began (2015).

6. El impreso F.8.38(2) de la biblioteca Chetham, a partir del cual se ha creado el registro ESTC S126711 en el English Short Title Catalogue de la British Library, es un bifolio incompleto, muy recortado, que sirvió como hoja de guarda en la encuadernación del ejemplar F.8.38(1). Vid. noticia bibliográfica 2 .

7. En la actualidad, no se localiza ningún ejemplar de esta edición compostelana de Luis de Paz, impresor que desarrolló toda su actividad en Santiago de Compostela entre los años 1578 y 1605 (vid. Delgado Casado 1996, n. ${ }^{\circ}$ 665). 
villages round about: Being first penned in Spanish verse, by Thomas de Mesa, inhabitant within the said city of Sivill, and imprinted in the city of S. Iames in Spaine, with licence from the Ordinary, in the house of Lewes de Paz. Anno. 1604. And now translated into english verse by W. St. the first of August. 1604 (vid. figura 2).

La segunda relación sobre la arriada de santo Tomé que consultó Palomo lleva la firma de Blas de las Casas Alés, ${ }^{8}$ vecino de Sevilla y testigo de vista del aquel trágico suceso. Este ingenio sevillano compuso en cuarenta y seis octavas reales la Cuarta relación de el (sic) avenida del río de Sevilla, que apareció publicada en esa misma ciudad al poco tiempo de haber ocurrido la catástrofe. Aunque esta crecida sobrevino el 20 de diciembre de 1603, la obra de Casas Alés se imprimió a principios del año siguiente, en formato $4^{\circ}$, de 4 hojas, en el taller de Francisco Pérez, en la calle de Martín Cerón. La última hoja de este pliego se completó, además, con un anónimo Romance del río de Sevilla, que Palomo valoró positivamente frente al «escaso mérito» de los versos de Casas Alés (1878, I: 213). Pese a la notable fama que debió alcanzar su relación, cuarta de una serie dedicada a la inundación del Guadalquivir, el único ejemplar conocido de esta edición hispalense se conserva actualmente en la biblioteca de uno de los herederos del duque de T'Serclaes (vid. figura 3). ${ }^{9}$ Su aparición en 1997, además de una grata sorpresa, supuso un feliz hallazgo bibliográfico porque ninguno de los repertorios consultados seńalaba la existencia de un ejemplar en la colección del duque. Sí sabíamos, en cambio, que su hermano el marqués de Jerez de los Caballeros tuvo un ejemplar de esta cuarta relación, a pesar de que nunca llegó a la Hispanic Society. ${ }^{10}$ Indagando en la tradición bibliográfica de esta edición, descubrimos que fue citada por primera vez, aunque sin localización de ejemplar, en el tomo segundo del Ensayo de Gallardo (1866), y a partir de él, recogieron la noticia Maffei y Rúa Figueroa (1873), Hazańas (1892) y Escudero (1894). A lo largo del siglo xx, además, le dieron entrada en sus respectivos repertorios Palau (1950), Agulló (1966), Simón Díaz (1967) y Domínguez Guzmán (1992). Y ahora, a la vista del ejemplar localizado, se puede consultar su descripción tipobibliográfica en mi catálogo de relaciones de sucesos del duque de T’Serclaes, n. ${ }^{\circ} 45$ (Gonzalo García 2018).

Indudablemente, por esta relación, Casas Alés también se contaría entre «la plaga que ha salido de poetas / a celebrar la inundación del Betis», según lo expresó Juan de la Cueva en su soneto 207 (Cebrián 1991: 39-40). Aunque son muy exiguos los datos que tenemos sobre nuestro autor, hay que señalar que compuso en quintillas de ciego una segunda obra titulada $A$ la Inmaculada Concepción de la Virgen Santíssima Maria madre de Dios y señora nuestra, concebida sin mancha de pecado original, la cual se imprimió en 1615 en Granada, en casa de Antonio René, en formato 4º,

8. En el pliego, solo consta su nombre de pila y primer apellido: «Blas de las Casas».

9. Vid. noticia bibliográfica 3.

10. De nuevo, el pliego está descrito en Rodríguez Moñino (1966: 38), pero no figura en Penney (1965). 
de 4 hojas. El vuelto de la última hoja se completó en esta ocasión con un soneto al mismo asunto, firmado igualmente de su mano y pluma, tal como se anticipaba en el título: Lleva al fin un soneto al Santissimo Sacramento y a la Limpissima Concepción. Compuesto todo por Blas de las Casas Alés, hijo de Sevilla. De esta edición granadina, se localizan actualmente seis ejemplares en distintas bibliotecas europeas, públicas y privadas. ${ }^{11} \mathrm{Y}$ nos consta que tanto Justino Matute y Gaviria (1886, I: 140-141) como el marqués de Jerez de los Caballeros poseyeron asimismo un ejemplar. ${ }^{12}$ Por su parte, Ángel Lasso de la Vega (1871: 208) también dio cuenta de este pliego de temática concepcionista al reseñar la obra de Casas Alés, al que identifica como el "fiscal, espíritu divino en lo divino y humano", de cierta academia establecida en Sevilla, según la cita de Luis Vélez de Guevara en su Diablo Cojuelo, tranco IX (1641). ${ }^{13}$

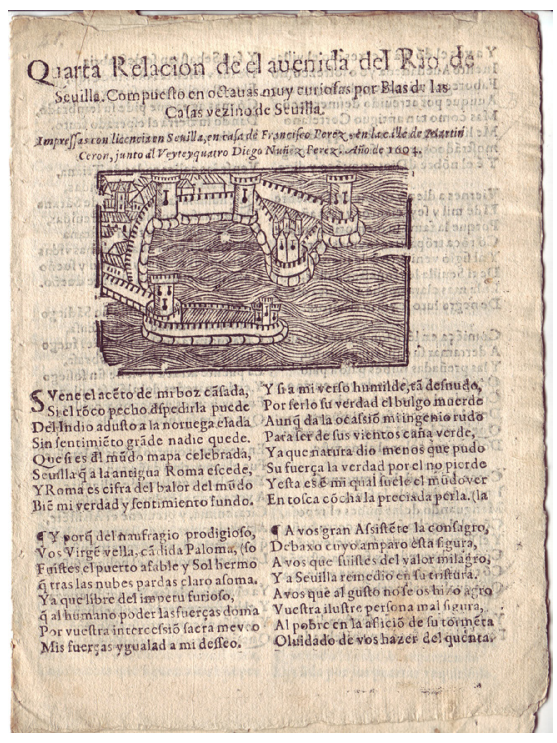

Figura 3

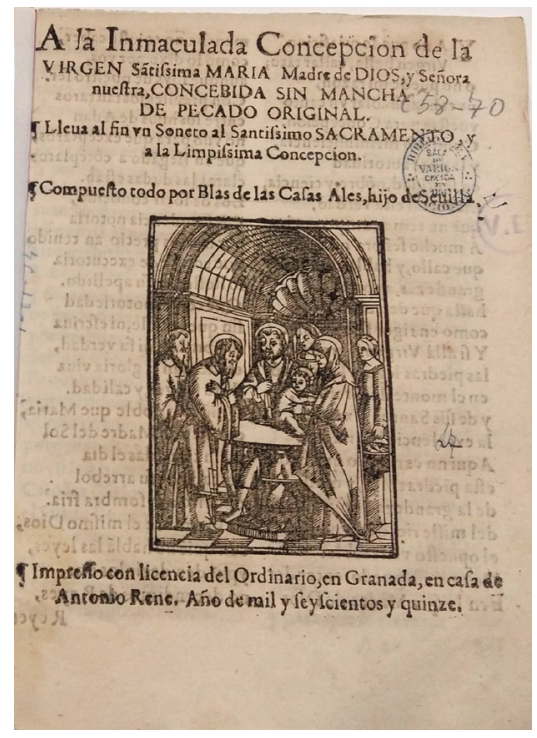

Figura 4

11. Albacete. Particular de D. Francisco Mendoza Díaz-Maroto (Mendoza Díaz-Maroto. Catálogo. Suplemento II, n. ${ }^{\circ}$ 24).- Córdoba. Diocesana, 17-R.002.772(10) (olim Est. 07 Caj. 32).- Évora. Pública, S.N.-E 44-C 4.- Londres. British Library, C.63.b.27(10).- Madrid. Nacional, VE-58(70) (vid. figura 4).- Sevilla. Colombina, 28-9-12(18). Cito estas bibliotecas de forma abreviada por el sistema establecido en Gonzalo García (2018).

12. El ejemplar del marqués de Jerez se conserva hoy en Nueva York. The Hispanic Society of America (vid. Rodríguez Moñino 1966: 38, y Penney 1965: 98).

13. Vid., al respecto, Hazañas (1888: 5). Otros méritos literarios de Casas Alés fueron aportados por Rodríguez Marín en sus dos monografías dedicadas al poeta antequerano Pedro Espinosa, a las que remite desde su edición del Diablo Cojuelo (1918). En primer lugar, en Pedro de Espinosa. Estudio biográfico, bibliográfico y crítico (1907: 276), anotó que «[...] el hispalense Blas de las Casas Alés, "espíritu divino en lo divino y humano", como le llamó años más tarde Luis Vélez de Guevara, 


\section{La avenida de san Benito en 1608}

De la inundación que asoló la capital hispalense en el equinoccio de primavera del año 1608, nos ha llegado información a través de varias fuentes manuscritas e impresas, desconocidas en su mayor parte para Palomo (1878, I: 221). Curiosamente, la «avenida de san Benito» — como así la bautizaré por haber ocurrido en el día de su festividad - no fue citada por Cabrera de Córdoba (1857) ni tampoco pasó a los Anales de Ortiz de Zúñiga (1677). Sin embargo, gracias a una anónima mano que quiso dejar memoria de este nuevo desastre natural, conocemos los efectos destructivos que tuvo para la ciudad de Sevilla:

En 21 de marzo, día de san Benito de dicho año, a las dos de la mańana, hubo tal tempestad en esta ciudad que hizo la puente muchos pedazos, y la estacada de la dicha puente la arrancó, y dio un tumbo con ella que docientos hombres no lo hicieran. Sacaba los hombres de los barcos, y al pontero echó al agua y se ahogó. Cinco almenas del castillo arrancó y echó en la puente. Quisieron decir fue obra del demonio. Hubo muertes de personas, ruinas de casas y cabos. ${ }^{14}$

demostró en 1628 la mucha estimación que profesaba á Espinosa, dirigiéndole una carta en que dió cuenta de la fiesta celebrada por el convento de San Francisco de Sevilla á la canonización de los mártires del Japón». De esta carta, que Francisco de Lyra imprimió en Sevilla en 1628, Rodríguez Marín pudo consultar un ejemplar en la biblioteca de T'Serclaes. Por otro lado, sus pesquisas bibliográficas también le llevaron a identificar a Blas de las Casas Alés como el posible autor del soneto acróstico insertado al inicio de La Casa del juego de Francisco de Navarrete y Ribera (1644), a pesar de que, en esta obra, aparecía con el nombre de Blas de las Casas Venegas. En segundo lugar, en su edición de las Obras de Pedro Espinosa, Rodríguez Marín realizó la siguiente afirmación: «[...] una dichosa casualidad me dió á conocer en la riquísima biblioteca sevillana de mi buen amigo el Sr. Duque de T'Serclaes un pliego manuscrito, quizás de la mano del hispalense Blas de las Casas Alés, en que éste dió la traza para un trofeo al Duque de Medina Sidonia, o bien fuera aquel mismo con que se solemnizó la traída de aguas, ó bien se destinara, y esto me parece más probable, para celebrar el restablecimiento de aquel príncipe tras algunas de sus graves dolencias, quizá de las tercianas que padeció en el invierno de 1629 y 1630» (1909: 409). Por su rareza bibliográfica, Rodríguez Marín decidió incluir justo a continuación la transcripción de este manuscrito (1909: 410-412).

14. Esta noticia consta en el f. $103 \mathrm{r}$ de un manuscrito de la Biblioteca Capitular de Sevilla, con signatura Mss. 59-1-3 (olim 84-7-19, olim B4a-449-30), que lleva por título Memorias eclesiásticas y seculares de la muy noble y muy leal ciudad de Sevilla (vid. figura 5). Aunque se trata del mismo volumen que consultó Palomo para reseñar la riada de 1608 (1878, I: 221), este investigador recogió un extracto diferente del suceso, que figura en los ff. 259 v-260 r y que transcribo a continuación: «En 21 de marzo de 1608, día de san Benito, a las dos de la mañana, hubo una gran tempestad y tormenta de viento y agua. Hizo pedazos la puente y arruinó la estacada della, y la volvió lo de abajo arriba, y echó al pontero al agua y se ahogó. Y arrancó del castillo de Triana cinco almenas y las arrohó $(s i c)$ sobre la puente, y hizo otros destrozos notables, sin llegar al montón de chamiza que está tan cerca, ni a los toldos de estera de las ostioneras, que cualquier soplo los destroza». Posiblemente, este copista se sirvió de otro manuscrito de la Colombina, con signatura Mss. 59-6-25 (olim 64-7-100), el cual fue editado parcialmente por Morales Padrón (1981: 16), y en concreto, la noticia de la riada de 1608 aparece en el f. 236 v (Ibidem: 27). Agradezco a Antonio Segura y a José Sáenz la amable ayuda que me han prestado a la hora de localizar estos documentos. 


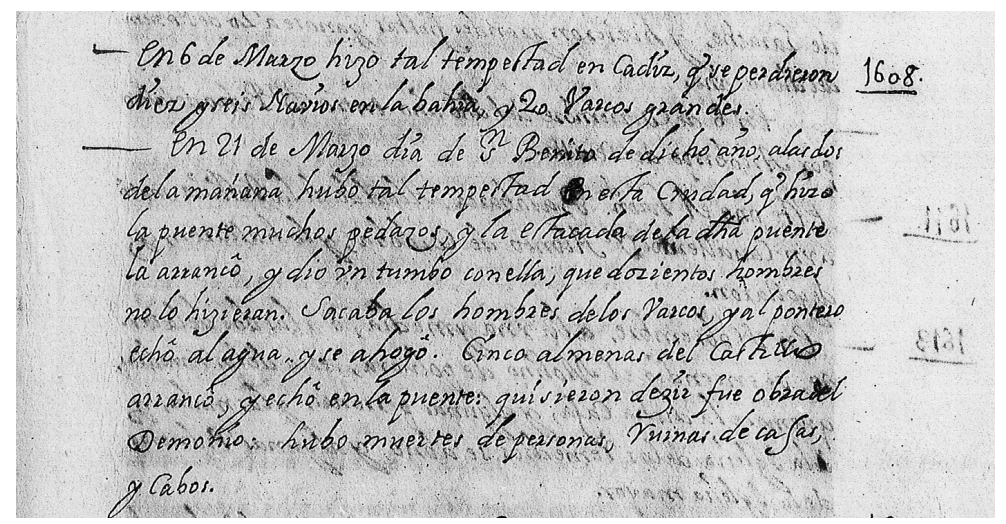

Figura 5

Esta no era la primera vez, ni sería la última, en que se venía abajo el inestable puente de barcas que unía a Triana con Sevilla (Alonso Franco et al. 1999: 11-19). En 1603, la rotura de este puente ya le había costado la vida a cientos de personas (Cabrera de Córdoba 1857: 206), entre ellas, a su capataz Juan de Lepe (Ariño 1873: 116). Por eso, en junio de 1604, el ingeniero italiano Tiburcio Spanoqui había presentado un proyecto, a instancias del cabildo sevillano, sobre los reparos que convenía hacer para mitigar los daños de las recurrentes crecidas del río. ${ }^{15} \mathrm{~A}$ pesar de ello, nada o muy poco se había logrado resolver al cabo de cuatro años. De forma súbita, la tragedia volvió a sacudir a la ciudad hispalense un 21 de marzo de 1608 y sus consecuencias fueron aún mayores de lo que aquel anónimo copista dejó anotado. Así nos lo revelan ahora dos inéditas relaciones de sucesos que constituyen la prueba irrefutable de la triple circulación —oral, manuscrita e impresa — de esta noticia.

La primera relación fue obra del licenciado Andrés Juan Gaitán, fiscal por aquel entonces del Tribunal del Santo Oficio de Sevilla. ${ }^{16}$ Como testigo ocular del

15. Palomo (1878, I: 125-127) utilizó como fuente de consulta este proyecto de Spanoqui, fechado en 25 de junio de 1604: Parecer que dio el comendador Tiburcio Spanoqui, Cavallero del hábito de San Iuan, ingeniero mayor de su Magestad, y gentilhombre de su casa. A la muy noble y muy leal ciudad de Seuilla sobre los reparos que conuienen para la inundación del río Guadalquiuir. Mandose imprimir por acuerdo de la ciudad de Seuilla. [S.l., s.i., s.a., pero: c. 1604, post. 25 jun.].- Fol.- $\mathrm{A}^{12}$ $\left[\mathrm{A}^{7+5}\right]$.- [1]2-12 f.- Sin marcar el lugar correspondiente al $\mathrm{f}$. 10. De esta edición, existe un ejemplar en la Academia de la Historia, con signatura 9-3765(8) ${ }^{\dagger}$. Sin embargo, el ejemplar que tuvo a la vista Palomo pertenece a otra edición sevillana, impresa por Francisco Pérez en 1604, ejemplar que hoy se conserva en la Biblioteca Nacional de Espańa, con signatura VE-31(12).

16. Este inquisidor ejerció la fiscalía del Tribunal sevillano desde 1606 hasta marzo de 1610, según explica García y García: «[...] recibe el nombramiento de fiscal del Tribunal del Santo Oficio de Cuenca, su primer destino como miembro de la Inquisición. Sin más referencias de este destino, permanece en él hasta el año 1606. Desde la fiscalía del Tribunal conquense, el Licencia- 
desastre, quiso contárselo a la autoridad homóloga en la ciudad de Cuenca para dar fe de todo lo que había sucedido aquella dramática noche en el castillo de Triana, sede y cárcel de la Inquisición en la capital hispalense. El licenciado Gaitán se encargó de trasladar al papel lo que él mismo había visto y oído, amén de lo que le habían contado otras fuentes fidedignas, y por esta razón, precisamente, su relato adquiere ahora un valor excepcional al darnos a conocer la intrahistoria del suceso. ${ }^{17}$ En la actualidad, la única copia manuscrita que se conoce de esta relación se custodia en la Biblioteca Nacional de España, con la signatura Mss. 18654(76) (olim G. 102-24 y G. 102-20, olim P.V. Fol. C. 25, n. 76), y lleva por título: Relación que el licenciado Andrés Juan Gaitán, fiscal del Santo Oficio de la Inquisición de Sevilla, envió a la ciudad de Cuenca de un terremoto que sucedió en la ciudad de Sevilla y Triana, a veintiuno de marzo deste año de 1608 (vid. figura 6). ${ }^{18}$

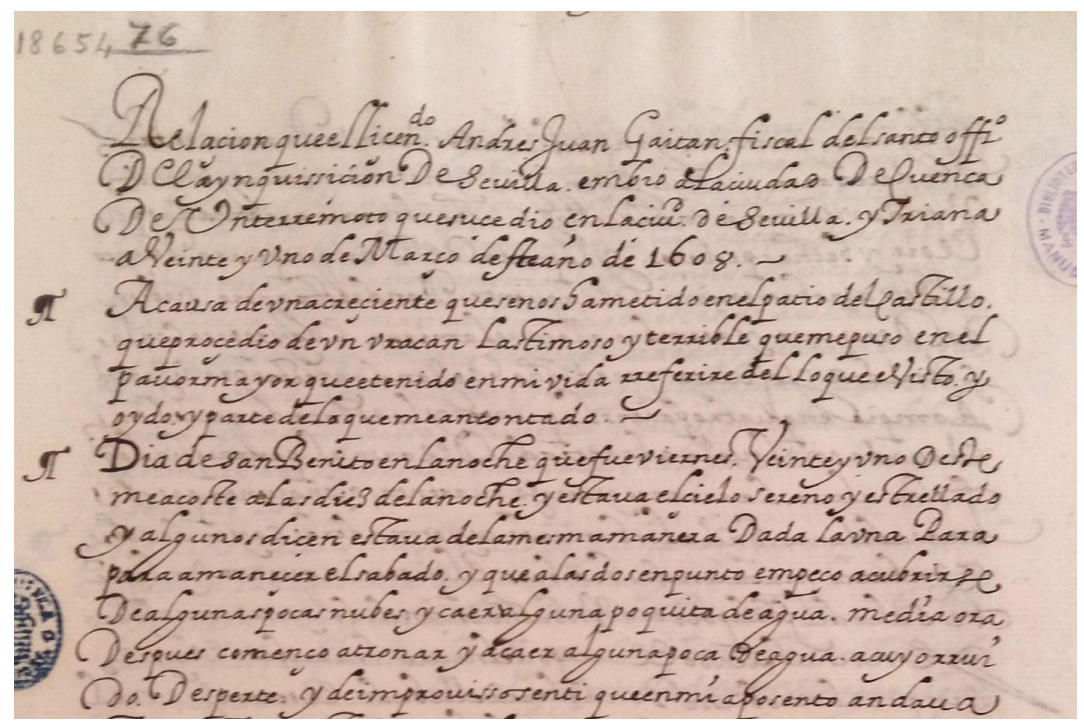

Figura 6

do Andrés Juan y Santaclara, que ahora se hace llamar Andrés Juan Gaitán, es promovido a la de Sevilla en donde ejerce hasta marzo de 1610; el 16 del mismo mes recibe el nombramiento de Inquisidor General Apostólico del Virreinato de Perú y obispo de Quito, con sede en Lima» (2018: 36). 17. Como bien apuntó González de Caldas, «el primer obstáculo con que tropezaban las aguas en el arrabal era su castillo. Se pueden suponer sus efectos demoledores en los viejos y remendados muros. Sin amparo posible, sufría la furiosa embestida del río, que comenzaba a filtrarse por cimientos y albañales hasta que terminaba entrando a caños, rompiendo a su paso puertas y ventanas. Su penoso estado durante la inundación y después de haber sufrido sus efectos, fue retratado por los inquisidores en numerosas cartas» (1985: 57).

18. De ella dieron noticia Maffei y Rúa Figueroa, n. ${ }^{o} 911$ (1872): «Ms. en 2 h. en fól. Bibliot. nac. cód. G. 102", señalando que parecía más bien la relación de un huracán. 
Según consta en ella, el licenciado Gaitán vivió con auténtico pavor el huracán que sobrevino en la noche del 21 de marzo, viernes, día de san Benito. ${ }^{19}$ Su narración es, en todo momento, elocuente y estremecedora. En primer lugar, cuenta con gran detalle cómo se despertó a las dos y media de la mañana, sorprendido por el ruido atronador de la tormenta y muy asustado al ver que la creciente anegaba el patio y las dependencias del castillo. Con el fin de ayudar a la gente que pedía socorro desde el río, dos compañeros de Gaitán colocaron rápidamente hachas en las ventanas de varios aposentos $\mathrm{y}$, después de llamar al portero para que les abriera la puerta del castillo, bajaron todos al callejón. Allí presenciaron, con asombro y espanto, el desplome y la destrucción de ocho almenas, una de las cuales cayó irremediablemente sobre el puente de barcas. La fuerza del viento fue de tal magnitud que, además de provocar la rotura del puente en cuatro partes, arrancó su estacada, desplazando los maderos de esta unos cuarenta o cincuenta pasos hasta caer sobre un barco, momento fatídico en el que murieron dos hombres. Asimismo, «arrancó la cruz que estaba delante de la puerta del castillo y no se sabe adónde la llevó» (f.1 v). El fiscal del Santo Oficio también vio morir al «que tenía cuenta con la puente», es decir, el pontero o tenedor-mantenedor del puente, ${ }^{20}$ al que «hallaron ahogado a las seis del día, herido en la cabeza y acardenalado brazos y cuerpo, con gran sentimiento — según confiesa Gaitán- de los que le conocimos, porque era hombre de bien» (f.1 v). Muchas otras cosas sucedieron aquella aciaga noche: choques y hundimientos de barcos, ruinas de casas, derribo de chimeneas, caídas de puertas y torres de iglesias, ${ }^{21}$ etc., de las que Gaitán tuvo conocimiento al oírlas él mismo, o mediante la certificación de otras personas. Así lo dejó consignado en su relación, tratando de asegurar la fiabilidad de sus fuentes, incluso las de segunda mano, ${ }^{22}$ y remitiendo a mejores cronistas para el relato de otros sucesos espantosos. ${ }^{23}$ Desde luego, en mi opinión, no creo que hubiera habido final más acertado para su narración que el que él mismo propuso: «Lo que falta a esta relación suplican en breve tiempo, a mi parecer, los ciegos con sus coplas, que es bonísima la materia para ellos» (f.2 v).

19. En realidad, de acuerdo con sus palabras, parece que todo debió suceder en la noche siguiente al día de san Benito: «[...] Día de san Benito en la noche, que fue viernes veintiuno deste, me acosté a las diez de la noche y estaba el cielo sereno y estrellado. Y algunos dicen estaba de la mesma manera dada la una para amanecer el sábado y que, a las dos en punto, empezó a cubrirse de algunas pocas nubes y [a] caer alguna poquita de agua. Media hora después, comenzó a tronar y a caer alguna poca de agua, a cuyo ruido desperté. Y de improviso, sentí que en mi aposento andaba tanta tempestad y ruido en puertas y ventanas que creí haberse entrado en él los cuatro elementos [...]» (f.1 r).

20. Vid., al respecto, «El tenedor del puente de barcas» (Pérez Aguilar 2013: 35-44).

21. En este punto, Gaitán añadió: «Olvidábame de decir a V. m. que la campana de la torre de san Román y la de san Isidro del Campo se llevó la tormenta a parte donde no han parecido» (f.2 r). 22. «Refiriómelo persona que lo supo de otra que se había hallado presente al caso, asegurando que se le podía dar crédito» (f.2 v).

23. «Derribó muchas chimeneas y algunas casas, con peligro de algunas personas, cuyos sucesos que son espantosos remito a mejor coronista» (f.2 r). 
Y en efecto, así lo prueba una segunda relación en verso, de la que me ha parecido oportuno dar a conocer su texto íntegro al final de este trabajo, por cuanto en ella se contienen otros muchos detalles del desolador episodio que vivió Sevilla aquel funesto día de san Benito. Sin embargo, antes de extractar su contenido, merecerá la pena recordar su particular historia bibliográfica.

Al filo del siglo xx, Manuel Serrano y Ortega, capellán de los hermanos Pérez de Guzmán y Boza, pudo consultar en la biblioteca del duque de T'Serclaes un curioso opúsculo en el que se refería la avenida del Guadalquivir de 1608. Así lo dejó descrito en el asiento n. 56 de su Bibliografía de la catedral de Sevilla (1901). Se trataba de una relación en verso y formato en $4^{\circ}$, de 4 hojas, sin datos editoriales, escrita por el maestro Diego de Brizuela Corcuera, "cura propio»" ${ }^{24}$ de la villa de los Pozuelos, en el campo de Calatrava, ${ }^{25}$ el cual se hallaba en Sevilla en el día en el que sobrevino la arriada. Como testigo de vista de este lamentable suceso, decidió narrar en metro de romance su Relación muy verdadera de la tempestad y huracanes, y temblores de tierra, que sucedieron en esta ciudad de Sevilla, día del señor San Benito, que se contaron veintiuno de marzo deste año de 1608, añadiéndole a la postre otro romance suyo dedicado al mismo santo.

Según he podido comprobar, Gallardo (1866) fue el primero en describir esta relación, aunque sin localizar ejemplar, y a lo largo de más de un siglo, su noticia fue recogida por Maffei y Rúa Figueroa (1872), Escudero (1894), Simón Díaz (1957, 1961 y 1973) y Agulló (1966). Además, por Rodríguez Moñino (1966: 33), sabíamos que el marqués de Jerez de los Caballeros también poseyó un ejemplar de esta misma edición, a pesar de que no consta en el catálogo de Penney (1965). Por su parte, Palau (1949) dio entrada a una relación con el mismo inicio de título, extensión y formato: Relación muy verdadera de la tempestad y huracanes y temblores de tierra que sucedieron en esta ciudad de Sevilla, pero apuntó su pie de imprenta: «Sevilla, M. Clavijo, 1608», consignando la existencia de un ejemplar procedente de la biblioteca de Henry Huth.

Aunque todo parecía indicar la existencia de dos ediciones diferentes del mismo texto, en ausencia de los ejemplares, Domínguez Guzmán, n. ${ }^{\circ} 103$ (1992), adjudicó los datos editoriales facilitados por Palau (a partir del ejemplar de Huth) a la edición sine notis descrita por Gallardo (y de la que Serrano y Ortega consultó un ejemplar en la biblioteca de T'Serclaes), contribuyendo a oscurecer la historia editorial de esta relación. De este modo, sin discriminar la existencia de dos ediciones, reunió bajo la misma entrada las citas abreviadas de los repertorios que ella había consultado (Gallardo, Escudero, Palau y Simón Díaz). Ahora, sin embargo, tras la reaparición de sendos ejemplares de ambas ediciones, no solo se confirma la información previa transmitida por Serrano y

24. Es decir, «párroco en propiedad de una feligresía» $(D L E)$.

25. Se trata de Los Pozuelos de Calatrava, municipio de la provincia de Ciudad Real. 


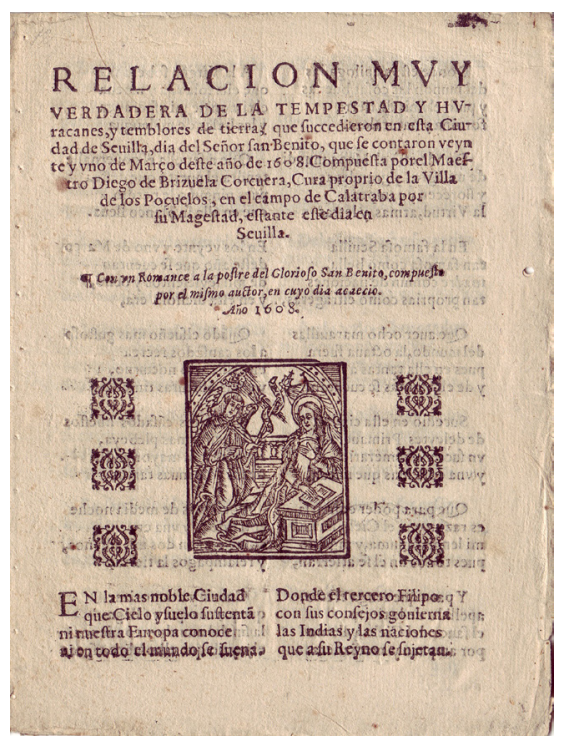

Figura 7

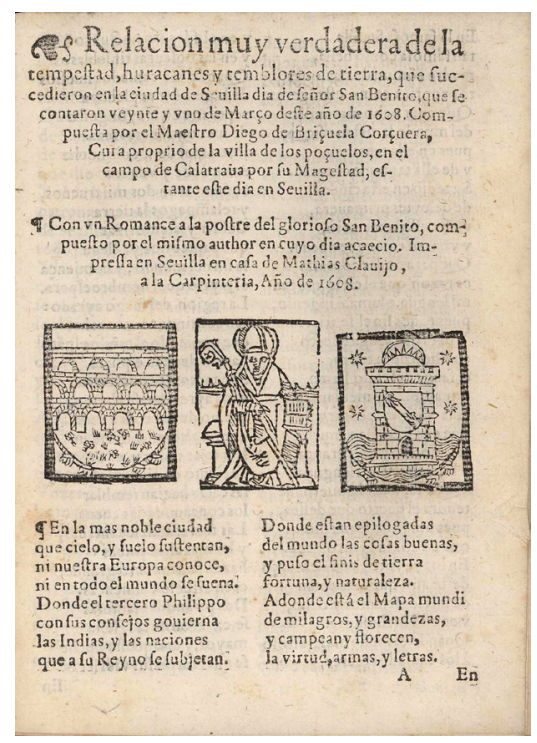

Figura 8

Ortega y Palau, sino que al fin es posible conocer el texto versificado de esta gran tormenta que asoló Sevilla en el equinoccio de primavera de $1608,{ }^{26}$ así como el de los correspondientes romances añadidos en cada edición. ${ }^{27}$

Mientras que el ejemplar de la edición sine notis procedente de T'Serclaes reapareció en 1997 en una biblioteca de sus herederos (vid. figura 7), ${ }^{28}$ el ejemplar de la edición sevillana que perteneció a Henry Huth y, posteriormente, a John Bagnell Bury y Michael Bury, fue adquirido por la Biblioteca Nacional de España doce años después, en 2009, por compra efectuada al librero londinense Paul Orssich, y se conserva en esta institución bajo la signatura topográfica VE-1492(1) (vid. figura 8).$^{29}$ Todo ello pude explicarlo así mismo en mi catálogo de relaciones de sucesos de la colección T'Serclaes, en donde ya se puede consultar la noticia tipobibliográfica de esta relación, n. ${ }^{\circ} 58$ y 58.1 (Gonzalo García 2018: 77-80).

26. Que afectó a su famosa iglesia mayor o catedral (vv. 81-84), y de ahí, precisamente, su inclusión en el repertorio de Serrano y Ortega, n. ${ }^{\circ} 56$ (1901).

27. En ambas ediciones, al romance principal le sigue otro dedicado a san Benito, escrito igualmente por Diego de Brizuela Corcuera, pero, en la edición sevillana de Matías Clavijo, se ha añadido también un "Romance nuevo en matraca a una dama sevillana», que ocupa su última hoja.

28. Vid. noticia bibliográfica 4.

29. Vid. noticia bibliográfica 5. Este ejemplar lleva los ex libris de «. B. Bury» y «Michael Bury» en la contratapa posterior, además del de Henry Huth, «Ex musæo Huthii», en la contratapa anterior. El pliego aparece descrito en los dos catálogos de la biblioteca de Huth (1880, V, p. 1660, y 1911, I, n. 1780). 
En cuanto al contenido, el relato de Brizuela Corcuera resulta muy revelador a la hora de sondear los daños materiales y personales que causó la crecida del Betis en 1608. En sentido estricto, su narración comienza en el v. 45, después de veinticuatro versos introductorios de carácter descriptivo y laudatorio a la ciudad de Sevilla, y de otros veinte versos invocatorios. En ese punto, el autor indica que todo sucedió de forma repentina en la noche del 21 de marzo, entre las doce y la una, a causa de una tempestad con truenos, relámpagos y rayos, que llegó acompañada de vientos de extraordinaria fuerza. Como consecuencia, la ciudad hispalense sufrió grandes pérdidas en edificios e iglesias. Según leemos, temblaron las casas, se cayeron cientos de tejados y chimeneas, se vinieron abajo dos pirámides de la catedral, se quebraron las vidrieras de esta iglesia y las de la colegial del Divino Salvador, se desplomaron la torre de la iglesia de san Isidoro y la del convento de las Vírgenes, se cayó al suelo la azotea de san Leandro y, finalmente, se rompieron las puertas del convento de Nuestra Señora del Valle y la puerta de Jerez. A la vista de Brizuela Corcuera, todo andaba alborotado y no se oían sino quejas, lamentos y gritos, especialmente de niños, mujeres y ancianos en su lucha por sobrevivir, incidentes lastimosos que imprimen a este relato un marcado carácter sensacionalista. En el furor del río, los marineros también vivieron episodios de auténtica desesperación por la quiebra, el choque y el hundimiento de sus embarcaciones. El viento hacía volar todo cuanto encontraba a su paso: bancos, mesas, puestos de mantenimiento, árboles, cepas, cruces y otras muchas cosas. Con su inmensa fuerza - tal como anotó el licenciado Gaitán-, el viento llegó a destruir el puente de barcas, que «se partió y se dividió / en muchas partes y piezas» (vv. 171-172). Con todo, la mayor novedad de este romance asoma a partir del v. 177, cuando Brizuela Corcuera ensalza la heroica actuación del Asistente de Sevilla, Bernardino de Avellaneda, ${ }^{30}$ que acudió al amanecer para poner remedio a tan dramática situación: «Mostró su grande valor / y su continua prudencia / este famoso Asistente: / ¡dos mil ańos él lo sea!» (vv. 191-196). Justo entonces, el autor nos informa de la muerte del pontero y otras muchas personas, así como de la caída de dos almenas del castillo de Triana. Además, por él nos enteramos de la trágica muerte «de dos queridas hermanas, / honestas, santas y buenas» (vv. 209-210), al caerles encima una pared de su casa, suceso triste y desgraciado con cierta reminiscencia de la historia de las santas vírgenes Justa y Rufina, patronas de Sevilla. Finalmente, haciendo caso omiso de otros episodios de dudosa veracidad, el párroco de la Villa de los Pozuelos clausura su romance pidiendo a Dios clemencia para que estos castigos sirvan de aviso y enmienda a todos los pecadores:

30. Bernardino de Avellaneda, Conde Castrillo (Aranda de Duero, Burgos, 1544-Madrid, 1629), fue uno de los más distinguidos generales de la Marina española al servicio de Felipe III y, entre 1603 y 1609, desempeñó el cargo de Asistente de la ciudad de Sevilla (DBE, sub voce «Avellaneda y Leiva, Bernardino de»). 
Roguemos a Dios del cielo

que, por su grande clemencia,

se duela desta ciudad

y no mire sus ofensas;

y que tan grandes azotes

sirvan de hoy más para enmienda

de los vicios y pecados

que en tan gran ciudad se encierran.

$Y$ pues que, en tan santo tiempo,

Dios quiso acordarse della,

saque Dios, por su bondad,

el fruto que della espera.

(vv. 237-248)

Y de este modo, la avenida de san Benito se transforma en un suceso prodigioso, es decir, una manifestación de la ira de Dios, que pretende avisar a los hombres para que se alejen del pecado, se arrepientan, se enmienden y consigan la salvación, pues solo así se podrá restituir el orden natural del universo (Gonzalo García 2006: 104). ${ }^{31}$

31. En este sentido, recordemos también lo que el anónimo copista apuntó sobre esta tempestad: "Quisieron decir fue obra del demonio». 


\section{Noticia bibliográfica sintética de las ediciones citadas sobre las riadas de 1603 y $1608^{32}$}

1

Mesa, Tomás de: Andelvvio (sic) y rvyna que hizo el rio Gvadalquiuir, en la ciudad de Seuilla, y Triana, y otros pueblos comarcanos, en veinte de diziembre deste año de mil y seiscientos y tres. Donde se da cuenta del mucho mal que hizo, derribando casas: ahogando gentes, echando a perder mucha suma de mercaderias, hundiendo nauios de trigo, y otras cosas. Y las grandes preuenciones que su señoría el Assistente, y sus justicias, hizieron para reparar los daños que hazia a la ciudad, juntamente con los señores Veintiquatros de la dicha ciudad. Compuesto por... vezino desta ciudad de Seuilla. [S.l., pero: Sevilla]. En casa de Fernando de Lara, en la calle de la Sierpe. 1603.

4o.- [ ] $]^{4}-4$ h.- L. red.

Inic. tip.- Texto en verso, a 2 cols.

Palomo. Riadas del Guadalquivir, I, p. 213.- Huth. Catalogue 1880, III, p. 960.- Gallardo. Ensayo, III, n. ${ }^{\circ}$ 3062.- Hazañas. Sevilla, p. 56.- Huth. Catalogue 1911-1920, IV, n. ${ }^{\circ}$ 4946.- PALAU, IX, n. ${ }^{\circ}$ 166.153: consignó el ejemplar de Huth.- Rodríguez Moñino. Marqués de Jerez, p. 100.- Simón Díaz. BLH, XIV, n.o 5665.- Domínguez Guzmán. Imprenta en Sevilla, n.o 32.- CCPBE, n. ${ }^{\circ} 001314360-3 .-$ CBDRS, n.o 0007025.

MADRID. Nacional, VE-1428(1) [Anotación manuscrita en su carpetilla de protección; proc.: ¿Juan Pérez de Guzmán y Boza, Duque de T’Serclaes de Tilly?] (Adquirido a Guillermo Blázquez Barbero, Madrid, 1998) ${ }^{\dagger}$

\section{2}

Siuill in Spayne. Or, A true report of a most strange and wonderfull inundation, or prodigious floud, which hapned at Siuill in Spayne, with the exceeding great ouerflowings of the riuer Wadalkier, and the great hurt that it did in the city of Siuill, Triana, and other villages round about: Being first penned in Spanish verse, by Thomas de Mesa, inhabitant within the sayd city of Siuill, and imprinted in the city of S. Iames in Spayne, with licence from the Ordinary, in the house of Lewes de Paz. Anno. 1604. And now translated into english verse by W. St. the first of August. 1604. London. Printed by Simon Stafford, dwelling in Hosier [Lane near Smithfield. 1604?].

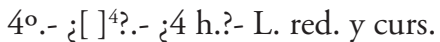

Texto en verso.

32. Además de ofrecer la descripción sintética y las características materiales de cada edición, aporto los datos mínimos de localización y procedencia de cada ejemplar. Asimismo, facilito la tradición bibliográfica de cada noticia siguiendo una secuencia cronológica y aplicando el sistema de fórmulas abreviadas de referencia que desarrollé en Gonzalo García (2010). 
CBDRS, n. ${ }^{\circ} 0007024$.

ManCHeSter. Chetham's Library, F.8.38(2) [Se conserva únicamente un bifolio incompleto, muy recortado, que sirvió como hoja de guarda en la encuadernación del ejemplar F.8.38(1): «Novus Jesuitismus hoc est paradoxa sive absurdissima Jesuitarum dogmata in singulis Christianae fidei articulis propris ipsorum verbis: cum notatione autorum, librorum, paginarum, ad scripturae coelestis veritatem antiquitatis orthodoxae puritatem, examinata à Christophoro Pelargo D. Francofurti. Apud Johannem Thymium. Typis Sciurinis. Anno 1608»] $]^{\dagger}$.

\section{3}

Casas Alés, Blas de las: Quarta relación de el (sic) auenida del río de Seuilla. Compuesto en octauas muy curiosas por... vezino de Seuilla. Seuilla. En casa de Francisco Pérez, en la calle de Martín Cerón, junto al Veyteyquatro (sic) Diego Núñez Pérez. 1604.

$4^{\mathrm{o}}$.- [ ] $]^{4} .-4$ h.- L. red. y curs.

Inic. tip.- Texto en verso, a 2 cols.

Gallardo. Ensayo, II, n. ${ }^{\circ}$ 1652.- Lasso de la Vega, p. 208, s/v Casas Alés (Blas de las).- Maffei y Rúa Figueroa, II, n. ${ }^{\circ}$ 4521.- Palomo. Riadas del Guadalquivir, I, p. 213.- Hazañas. Sevilla, p. 81.- Escudero, n. ${ }^{\circ}$ 884.- Rodríguez Marín. Pedro Espinosa, pp. 276-277, notas 1-2.- Palau, III, n.o 47.034.- Rodríguez Moñino. Marqués de Jerez, p. 38.- Agulló. Relaciones de sucesos, I, n. ${ }^{\circ}$ 406.- Simón Díaz. BLH, VII, n.o 6098.- Domínguez GuzMán. Imprenta en Sevilla, n. ${ }^{\circ}$ 47.- CBDRS, n. ${ }^{\circ} 0006959$.

Madrid. Biblioteca de los herederos del Duque de T'Serclaes, A, Caja 1, n. 7 [Numeración ms. a lápiz en el margen sup. de la primera plana: «41»; proc.: Juan Pérez de Guzmán y Boza, Duque de T'Serclaes de Tilly] (Gonzalo García. El legado bibliográfico del duque de T'Serclaes, n. $\left.{ }^{\circ} 45\right)^{*}$.

\section{4}

Brizuela Corcuera, Diego de: Relación mvy verdadera de la tempestad y huracanes, y temblores de tierra, que succedieron (sic) en esta ciudad de Seuilla, día del señor San Benito, que se contaron veynte y vno de março deste año de 1608. Compuesta por el maestro..., cura proprio de la villa de los Poçuelos, en el campo de Calatraba por su Magestad, estante este día en Seuilla. Con vn romance a la postre del glorioso San Benito, compuesto por el mismo auctor, en cuyo día acaeció. [S.l., s.i., s.a., pero: c. 1608, post. 21 marzo].

$4^{\mathrm{o}} .-\mathrm{a}^{4}\left[\mathrm{a}^{\mathrm{i}+2}\right]$.- 4 h.- L. red. y curs.

Inic. tip.- Texto en verso, a 2 cols.

Gallardo. Ensayo, II, n. ${ }^{\circ}$ 1486.- Maffei y Rúa Figueroa, I, n. ${ }^{\circ}$ 290.- Escudero, n. ${ }^{\circ}$ 914.- Serrano Ortega. Bib. catedral Sevilla, n. ${ }^{\circ}$ 56: consultó el 
ejemplar de T’Serclaes.- Simón Díaz. Relaciones (1540-1650), n.o 16.- Simón Díaz. BLH, VI, n. ${ }^{\circ}$ 5504.- Rodríguez Moñino. Marqués de Jerez, p. 33.Agulló. Relaciones de sucesos, I, n. ${ }^{\circ}$ 450.- Simón Díaz. Libros a buscar, XXX, n. ${ }^{\circ}$ 773.- Domínguez GuzMÁn. Imprenta en Sevilla, n. ${ }^{\circ} 103$ : sin discriminar la existencia de dos ediciones, pues adjudicó a la sine notis los datos de pie de imprenta de la edición sevillana consignada por Palau a partir de Huth (vid. infra 5).- CBDRS, n. ${ }^{\circ} 0007016 \mathrm{~A}$.

Madrid. Biblioteca de los herederos del Duque de T'Serclaes, A, Caja 1, n. ${ }^{\circ} 11$ [Numeración ms. a lápiz en el margen sup. interno de la primera plana: «12»; proc.: Juan Pérez de Guzmán y Boza, Duque de T'Serclaes de Tilly] (Gonzalo García. El legado bibliográfico del duque de T'Serclaes, n. $\left.{ }^{\circ} 58\right)^{*}$.

\section{5}

Brizuela Corcuera, Diego de: Relación muy verdadera de la tempestad, huracanes y temblores de tierra, que succedieron (sic) en la ciudad de Seuilla día de (sic) señor San Benito, que se contaron veynte y vno de março deste año de 1608. Compuesta por el maestro..., cura proprio de la villa de los Poçuelos, en el campo de Calatraua por su Magestad, estante este día en Seuilla. Con vn romance a la postre del glorioso San Benito, compuesto por el mismo author en cuyo día acaeció. Seuilla. En casa de Mathías Clauijo, a la Carpintería. 1608.

$4^{\mathrm{o}}$.- $\mathrm{A}^{4}\left[\mathrm{~A}-\mathrm{A}^{2-3-4}\right]$.- 4 h. - L. red.

Aparecen marcadas con sign. las cuatro hojas.

Inic. tip.- Texto en verso, a 2 cols.- Con recl.

Palau, II, n.o 36.063: consignó el ejemplar de Huth.- Gonzalo García. El legado bibliográfico del duque de T'Serclaes, n. ${ }^{\circ}$ 58.1.- CCPBE, n. ${ }^{\circ} 001298668-$ 2.- CBDRS, n. ${ }^{\circ} 0007016 \mathrm{~B}$.

Madrid. Nacional, VE-1492(1) [Ex museo Huthii; ex libris "J. B. Bury" y "Michael Bury"; proc.: Henry Huth] (Adquirido a Paul Orssich en 2009) (Нuth. Catalogue 1880, V, p. 1660; Huth. Catalogue 1911-1920, I, n.o 1780) ${ }^{\dagger}$. 


\section{Nota a la edición del texto}

Por ser el primer testimonio poético conocido de la avenida del Guadalquivir en 1608 , edito el texto de la relación compuesta por Diego de Brizuela Corcuera, tomando como base la edición sine notis del duque de T'Serclaes, que ofrece la versión más exacta (en adelante, $S n$ ), e incluyendo las variantes que presenta la edición sevillana (en adelante, $S$ ) en el apartado final de notas textuales. En este lugar, cada lectura va precedida del número de línea que ocupa en el texto. De modo sistemático, separo las lecturas de $S n$ de las variantes de $S$ mediante un corchete de cierre. Si se consignan lecturas diferentes, estas aparecen separadas por doble barra oblicua. Y siempre que sigo la lección de $S$, o corrijo con la ayuda de este testimonio, lo aclaro entre corchetes.

En la transcripción del texto, sigo los criterios fijados por el grupo de investigación SIELAE <https://www.bidiso.es/sielae/presentacion.htm> para la edición de relaciones de sucesos (Nider y Pena Sueiro 2019). Se ofrece así un texto modernizado, en el que se han adaptado los fenómenos gráficos propios del momento en que fue escrita la obra a los usos vigentes. De acuerdo con estos criterios de transcripción, se ha optado por la resolución de abreviaturas, sin más indicación; la sustitución de $\int$ alta por $s$; la restitución de $u$ para la $v$ vocálica y de $v$ para la $u$ consonántica; la transcripción de $y$ con valor vocálico por $i$; la normalización del resto de grafemas y la simplificación de dobles grafías de acuerdo con los usos actuales. No obstante, se han mantenido los grupos aglomerados de uso común y sistemático en los impresos: deste, della... Por lo que se refiere a la atildación de palabras, el uso de mayúsculas y la puntuación del texto, se han seguido las actuales normas académicas.

Por último, se ha respetado la disposición tipográfica del pliego, manteniendo la separación en forma de estrofas de cuatro versos en cada romance, y se ha indicado, en cada momento, la foliación del impreso. 


\section{[Relación de la avenida de san Benito en 1608]}

Relación muy verdadera de la tempestad, huracanes y temblores de tierra que sucedieron en esta ciudad de Sevilla, día del señor san Benito, que se contaron veinte y uno de marzo deste año de 1608. Compuesta por el maestro Diego de Brizuela Corcuera, cura proprio de la villa de los Pozuelos, en el campo de Calatrava por su Majestad, estante este día en Sevilla. Con un romance a la postre del glorioso san Benito, compuesto por el mismo autor, en cuyo día acaeció. Año 1608.

En la más noble ciudad que cielo y suelo sustentan, ni nuestra Europa conoce

4 ni en todo el mundo se suena;

donde el tercero Filipo, ${ }^{33}$ con sus consejos, gobierna las Indias ${ }^{34} \mathrm{y}$ las naciones

8 que a su reino se sujetan; $\left.\right|^{[a] 1 v}$

donde están epilogadas, del mundo, las cosas buenas, y puso el finis de tierra ${ }^{35}$

12 fortuna y naturaleza;

donde está el mapamundi de milagros y grandezas, y campean y florecen

16 la virtud, armas y letras;

en la famosa Sevilla, tan famosa como bella, madre común de naciones,

20 tan proprias como extranjeras,

que, [a] haber ${ }^{36}$ ocho maravillas

33. Felipe III (Madrid, 1578-1621), hijo de Felipe II y de Ana de Austria, fue rey de España y Portugal desde el 13 de septiembre de 1598 hasta el 31 de marzo de 1621.

34. Durante más de doscientos años (1503-1717), Sevilla fue la sede de la Casa de la Contratación, institución creada para defender el monopolio del comercio español con las Indias, la denominada «Carrera de Indias» (Laviana Cuetos 2006).

35. finis de tierra: fin, término de la tierra (lat. finis terrae).

36. que, [a] haber: considero necesaria esta adición, teniendo en cuenta el sentido y la medida del verso, pues es de suponer que el autor embebería la preposición en la sinalefa. Según $D L E$, la preposición $a$ «ante infinitivo, en expresiones de sentido condicional, equivale a la conjunción $s i$ con indicativo o subjuntivo». Esta misma estructura se refleja en el v. 41. 
del mundo, ${ }^{37}$ la octava fuera, pues en ella tantas hay

24 y de ella tantas se cuentan,

sucedió en esta ciudad, de deleites primavera, un suceso temerario

28 y una cosa más que nueva,

que, para poder contarla, es razón que el cielo mueva mi lengua, pluma e ingenio,

32 pues todos sin él se atierran. ${ }^{38}$

Y para que tenga efecto apellido $^{39}$ de la tierra, el favor del cielo llamo,

36 por amparo y medianera,

a la Virgen soberana, que ella sola rija y mueva el timón de mi esperanza

40 y las velas de mi lengua;

que, a ser ella el gobernalle, ${ }^{40}$ tendrá el puerto que desea, pues ninguno le perdió ${ }^{41}$

44 que en ella su blanco lleva.

En los veinte y uno de marzo deste ańo que se cuentan de mil seiscientos y ocho,

48 y en esta dichosa era,

cuando el sueño más gustoso

a los cansados recrea

en el silencio nocturno

52 y en las oscuras tinieblas;

37. Entiéndase la lista de las siete maravillas del mundo antiguo, que fueron retratadas por el pintor flamenco Maarten van Heemskerck y difundidas mediante estampas en el siglo XvI (Maarten van Heemskerck 2017).

38. se atierran: se derrumban, caen por tierra, en el sentido de «abatir», segunda acepción de aterrar $^{1}$ (de tierra) (DLE).

39. apellido: invocación, en el sentido de «llamamiento, llamada, convocación» (Aut.).

40. gobernalle: «El timón con que se gobierna el navío» (Aut.).

41. le perdió: lo perdió (el puerto); se refiere a que nadie que tenga puesto el blanco en la Virgen soberana dejará de alcanzarlo, es decir, de llegar al puerto que desea. 
cuando los cansados huesos

de la gente más plebeya

reposan con mayor gusto

56 de sus continuas tareas;

poco más de media noche, entre doce y una era, comenzaron dos mil truenos

60 y relámpagos la tierra

cubrir $^{42}$ y atemorizar, que parece que ya llega la fin del mundo y comienza

64 el juicio que el hombre espera. $\left.\right|^{\mathrm{a} 2 \mathrm{r}}$

La región del fuego airado tan continuos rayos echa que, poniendo al mundo espanto,

68 parece dejar su esfera.

Son tantos los huracanes y los aires que se alteran que no dejan cosa a vida ${ }^{43}$

72 que no alteren y no muevan.

Las tejas de los tejados de ciento en ciento se llevan, las casas hacen temblar,

76 los cóncavos y las cuevas.

Las torres más levantadas y las más altas zoteas $(\text { sic })^{44}$ hacen sentimiento grande,

80 caen al suelo chimeneas.

Dos pirámides famosas se cayeron de la Iglesia Mayor $^{45} y$, en aquesta noche, 84 se quebraron sus vidrieras.

42. cubrir: entiéndase a cubrir; se justifica la ausencia de la preposición por exigencia métrica.

43. a vida: respetando la vida $(D L E)$.

44. zoteas, por azoteas; se justifica la aféresis por exigencia métrica. Este mismo fenómeno fonético se repite en el v. 102.

45. Se refiere a la catedral de Sevilla. Gestoso consultó sus Libros de fábrica y dejó constancia documental de varios reparos efectuados en algunas vidrieras en los años inmediatos a la riada de 1608 (1890, II: 172-173). 
En San Salvador, ${ }^{46}$ también

hizo las vidrieras piezas

el aire, y notable daño

88

en monasterios e iglesias.

¿Qué diré del campanario

de San Isidro ${ }^{47}$ La fuerza

del viento - dicen - fue tanta

92 que dio con él en la tierra.

Y el de las benditas Vírgenes, ${ }^{48}$

patronas y medianeras

de Sevilla, sin reparo, ${ }^{49}$

96 todo junto al suelo vuela.

Y las puertas de Jerez, ${ }^{50}$

cerradas por dentro y fuera,

se rompen $[y],{ }^{51}$ en San Francisco, ${ }^{52}$

100 se abrieron las de la iglesia.

Del glorioso San Leandro, ${ }^{53}$

46. Se refiere a la primitiva iglesia colegial del Divino Salvador (otrora mezquita de Ibn Adabbas), que fue derribada en 1671 porque amenazaba ruina, la cual tenía dos vidrieras mayores que daban a la plaza del Salvador. Así lo dejó consignado Gestoso (1892, III: 342-344) después de haber consultado en la biblioteca del duque de T'Serclaes el manuscrito del sevillano Tirado de Aldana (1726), que pudo ver este templo antes de su derribo. Aunque se desconocía desde entonces el paradero de este manuscrito, hoy sabemos que fue adquirido por la Biblioteca Nacional de España en 2005 a través de la casa de subastas El Remate (su signatura topográfica es Mss. 23130-1).

47. Podría referirse a la torre de la iglesia de san Isidoro (Gestoso 1889, I: 144-145; Arana de Varflora 1789: 34), aunque el licenciado Gaitán — como ya he adelantado—apuntó la caída de la torre del convento de san Isidoro del Campo (Arana de Varflora 1789: 43-44).

48. Debe referirse a la iglesia del desaparecido convento de santa Justa y santa Rufina, patronas de Sevilla, más conocido como el de las Vírgenes, fundado en 1588 por Alonso Fajardo de Villalobos, obispo de Esquilache, aunque no hay constancia documental de que tuviera torre (Arana de Varflora 1789: 63). No obstante, también podría tratarse de la iglesia de la Trinidad, exconvento de religiosos trinitarios, en cuyos sótanos, según reza la tradición, debieron de estar presas las santas vírgenes Justa y Rufina (Morgado 1587, 129-131).

49. sin reparo: sin consideración, precipitadamente; pero quizá aquí podría significar 'sin defensa', en el sentido de «cosa que se pone por defensa o resguardo» $(D L E)$, es decir, se cayó la torre porque no estaba suficientemente protegida.

50. La antigua puerta de Jerez, así llamada porque en ella se iniciaba el camino de Sevilla hacia Jerez de la Frontera, fue una de las quince puertas de acceso al recinto amurallado de la ciudad hispalense en el siglo xvi (Morgado 1587: 44-45). Esta puerta mantuvo su aspecto medieval hasta mediados del siglo xIx (Albardonedo Freire 2002: 281-285).

51. Considero necesaria la adición de la conjunción $y$, teniendo en cuenta el sentido y la medida del verso. 52. Debe referirse a la iglesia del desaparecido convento casa grande de san Francisco (Arana de Varflora 1789: 39-41).

53. Se trata de la iglesia del convento de san Leandro (Arana de Varflora 1789: 57). 
caen en suelo las zoteas $($ sic),

y de la Virgen del Valle, ${ }^{54}$

104 las puertas también se quiebran.

Anda todo alborotado:

no se oyen sino quejas,

voces, gritos, alaridos

108 que causaban grande pena.

Voces dan niños y viejos,

las mujeres y doncellas,

los ternecitos infantes,

112 de temor, dejan las tetas.

Unos salen de sus casas,

huyendo la puerta fuera, pensando de (sic) se escapar

116 desta tan grande tormenta.

Otros llaman sus amigos porque ${ }^{55}$ a socorrerlos vengan; dejan otros sus mujeres,

120 hijos, casas y haciendas. $\left.\right|^{\mathrm{a} 2 \mathrm{v}}$

No socorre el padre al hijo, los hijos los padres dejan, todos buscan su remedio,

124 cada cual por su vereda.

A los que salen huyendo de sus casas y sus tiendas, buscando remedio, entienden

128 que las piedras montes eran.

Otros, temiendo la muerte, confesión piden apriesa, ${ }^{56}$ apriesa piden remedio

132 al cielo con grandes quejas.

Fue semejante este estrago al que de Roma se cuenta $\mathrm{y}$ al de la famosa Troya

54. Se trata de la iglesia del convento de Nuestra Señora del Valle (Arana de Varflora 1789: 48).

55. porque: valor final.

56. apriesa: aprisa, con rapidez. 
136 que sucedió por Elena. ${ }^{57}$

De las urcas ${ }^{58}$ y las naves que en el río están, se quiebran con el gran viento las jarcias, ${ }^{59}$

140 las proas, velas y entenas. ${ }^{60}$

Topetan $^{61}$ unas con otras, ya se hunden, ya se anegan, unas van el río abajo,

144 otras dan en el arena.

Voces dan los marineros, al cielo llegan sus quejas, no ay nadie que los entienda

148 ni quien socorrerlos pueda.

A las barcas más pequeñas, las áncoras ${ }^{62}$ se les quiebran y van a dar a lo fondo ${ }^{63}$

152 como caballo sin rienda.

Vuelan en el Altozano ${ }^{64}$

dos mil bancos, dos mil mesas, de fruteros, panaderos,

156 tenderos y freideras. ${ }^{65}$

Es cierto que se arrancaron árboles de la ribera

de cuajo, con el grande aire,

160 y de las viñas, las cepas.

De los calvarios, las cruces

se llevaba el aire enteras,

57. Se compara el estrago de esta riada con el del saco de Roma (1527) y el de la guerra de Troya (1194-1184 a. C.).

58. urcas: «Embarcación grande, muy ancha por el centro, y que sirve para el transporte de granos y otros géneros» $(D L E)$.

59. jarcias: "Conjunto de cabos y cables que forman parte del aparejo de un buque de vela» (DLE).

60. entenas: lo mismo que antenas, en el sentido de «vara a la que se asegura la vela» $(D L E)$.

61. topetan: topan, chocan.

62. áncoras: anclas de la embarcación.

63. a lo fondo: al fondo.

64. En el sitio del Altozano, situado a la entrada del puente por la parte de Triana, era donde se establecían los puestos de mantenimiento (Arińo 1873: 57).

65. freideras: en el sentido de freidora, "persona que fríe pescado para venderlo» $(D L E)$. Aunque no lo recoge $A u t$., se documentan varios casos de freidera en CORDE. 
cual fue la cruz del Compás ${ }^{66}$

$164 \mathrm{y}$ otras muchas que se cuentan.

$\mathrm{Y}$ aquella famosa puente

de Triana ${ }^{67}$ pasajera,

más que Córdoba a Castilla ${ }^{68}$

168 con sus ventas de Alcolea,

puente casi milagrosa

por su traza y su grandeza,

se partió y se dividió

172 en muchas partes y piezas.

Cosa que a no se poder

desto que digo hacer prueba, aunque mucho se afirmara,

176 no es posible se creyera. | a3 r

Acude, en amaneciendo, el ${ }^{69}$ famoso Avellaneda, Asistente de Sevilla, ${ }^{70}$

180 al remedio desta quiebra.

Y cual padre piadoso

de su república empieza,

con ánimo varonil,

66. Por compás se puede entender el «territorio o distrito señalado a un monasterio y casa de religión», o bien el «atrio o lonja de una iglesia o convento» (DLE). Según el relato del licenciado Gaitán, sabemos que el viento arrancó una cruz que estaba delante de la puerta del castillo de Triana. Aun así, Brizuela Corcuera podría referirse aquí al «Compás de la mancebía», la principal zona de prostitución en la Sevilla de finales del siglo xvı y principios del xvir. Situado entre la puerta del Arenal y la de Triana, el Compás estaba aislado del resto de la ciudad por la muralla y una tapia. Como era un lugar bajo, que se anegaba con mucha facilidad, también se le llamó "Compás de la laguna» (Morales Padrón 1977: 120). Desde principios del siglo XviI, la mancebía sevillana empezó a sufrir el acoso de los padres jesuitas y, según apunta Deleito y Pińuela (1959: 52-53), el arzobispo Pedro de Castro hizo levantar a la puerta del Compás un altar con un crucifijo con el ánimo de ahuyentar a los devotos. Aunque esto debió de ocurrir a partir de la llegada de este prelado a Sevilla en 1609, puede que, con anterioridad, ya se hubiera colocado alguna cruz en ese mismo lugar.

67. Se trata del antiguo puente de barcas sobre el Guadalquivir, que comunicaba Sevilla con Triana, cuya historia va ineludiblemente unida a la sucesión de riadas y roturas (Alonso Franco et al. 1999: 11-19).

68. Entiéndase más que el de Córdoba a Castilla, con clara alusión al antiguo puente romano que atravesaba el Guadalquivir a la altura de Alcolea, a escasos kilómetros de Córdoba, en cuyas proximidades había ventas para viajeros (Ponz 1791: 275-276). Tal como se documenta en este romance, puente era nombre ambiguo que se empleaba comúnmente en femenino.

69. Corrijo el lapsus del cajista, que colocó el artículo $e l$ al final del v. 177.

70. Como ya he señalado, Bernardino de Avellaneda desempeñó el cargo de Asistente de la ciudad de Sevilla entre 1603 y 1609 (DBE, sub voce "Avellaneda y Leiva, Bernardino de»). 
184 cuidar $^{71}$ del remedio della.

Manda luego se aderece

la puente con grande priesa $^{72}$

y que vengan oficiales,

188 los necesarios, a ella;

que se hagan los reparos ${ }^{73}$

luego al punto que convengan,

$\sin$ mirar a costa ${ }^{74}$ alguna,

192 sino al bien de aquesta tierra.

Mostró su grande valor

y su continua prudencia

este famoso Asistente:

196 ¡dos mil años él lo sea!

El pontero ${ }^{75}$ y otros muchos

se anegaron; ${ }^{76}$ dos almenas

del castillo de Triana ${ }^{77}$

200 derribó el aire en tierra.

Muchas casas y edificios, dentro en la ciudad y fuera, temblaron, y se cayeron

204 muchos balcones y rejas.

$\mathrm{Y}$ entre las cosas penosas

que deste estrago se cuentan, no es razón que aquí se pase

208 una muerte lastimera

71. cuidar: entiéndase a cuidar; se justifica la ausencia de la preposición por exigencia métrica.

72. priesa: prisa.

73. reparos: en el sentido de «la obra que se hace en las fábricas u otras cosas que padecen alguna ruina, o tienen necesidad de componerse o renovarse, o padecen menoscabo" (Aut.).

74. costa: coste, "cantidad que se da o se paga por algo" $(D L E)$.

75. pontero: se trata del encargado del puente, si bien este término no está recogido en Aut. ni en $D L E$, y tampoco aparece ningún caso en $C O R D E$. En cambio, sí está documentado el término tenedor para referirse al responsable del mantenimiento del puente de barcas de Triana, tan frecuentemente inutilizado por las sucesivas crecidas del río (Alonso Franco et al. 1999: 12-13, y Pérez Aguilar 2013: 35-44). Este cargo solía recaer en el maestro mayor de las atarazanas y se concedía por periodos de diez años (Martínez de Aguirre 1991: 12-13).

76. se anegaron: se ahogaron.

77. Se trata del castillo de Triana, más conocido como castillo de san Jorge, que fue sede y prisión del Santo Oficio en Sevilla durante tres siglos (1481-1785). En palabras de González de Caldas, «se levanta en Triana un testigo de excepción de las arriadas: su castillo, sede de la Inquisición de Sevilla desde 1480. Construido al borde del Guadalquivir, sufrió como ningún otro edificio su castigo, y con él sus moradores, presos e inquisidores» (1985: 58). 
de dos queridas hermanas, honestas, santas y buenas, muy amadas en su vida

212 y en la muerte compañeras;

en hábito de beatas, haciendo una vida austera, recogida y celestial,

216 ejemplo de las doncellas;

su conversación en Dios, sirviendo a Dios muy de veras, haciendo vida ejemplar,

220 más celestial que terrena;

continuando el sacramento del altar y penitencia, con gran ejemplo de todos,

224 de su vida tan honesta;

esta noche, con el aire, sobre ambas cayó entera una pared de su casa

228 y las mató: ¡cosa fiera! ${ }^{17}$

Causó a todos gran dolor la muerte destas doncellas, por ser de todos queridas

232 y por ser ellas tan buenas. |a3v

Otras mil cosas se dicen al parecer verdaderas, que, porque no lo son tanto,

236 no es razón que se refieran.

Roguemos a Dios del cielo que, por su grande clemencia, se duela ${ }^{79}$ desta ciudad

240 y no mire sus ofensas;

y que tan grandes azotes ${ }^{80}$

78. fiera: horrorosa, terrible.

79. se duela: se compadezca.

80. azotes: calamidades, castigos. 
sirvan de hoy más ${ }^{81}$ para enmienda

de los vicios y pecados

244 que en tan gran ciudad se encierran.

Y pues que, en tan santo tiempo,

Dios quiso acordarse della,

saque Dios, por su bondad,

248 el fruto que della espera.

FIN. $\left.\right|^{\text {a } 4 \mathrm{r}}$

\section{Romance al glorioso y bienaventurado san Benito}

En un áspero desierto,

en una fragosa sierra,

en las alturas de un monte,

4 en una profunda cueva,

donde los fieros bramidos

de las impacientes fieras,

en el cavernoso hueco,

8 distintamente resuenan,

aquel bendito Benito,

aquel divino profeta,

libre del golfo del mundo,

12 al dulce puerto navega.

Puesto en el norte su vista, pierde de vista la tierra, y de la empinada gavia, ${ }^{82}$

16 a sus forzados esfuerza.

Si, por su descuido, el aire alguna jarcia le quiebra, reconociendo su culpa,

20 él mesmo se da la pena.

$\mathrm{Si}$, en medio de su bonanza,

el mar furioso se altera,

solo a los remos acude

24 y amaina la hinchada vela.

81. de hoy más: desde este día.

82. gavia: «Vela que se coloca en uno de los masteleros de una nave, especialmente en el mastelero mayor» $(D L E)$. 
A todos los caminantes que sulcando ${ }^{83}$ el mar encuentra, los malos pasos les dice

28 y el buen camino les muestra:

que tengan por engañoso el canto de las sirenas, que no teman los estrechos

32 que están en la vida estrecha.

Al fin el santo glorioso, habiendo vivido en ella, de sus sabrosos trabajos

36 el dulce premio desea.

Y al tiempo de recebirle, la triste muerte le alegra, por ser el ligero barco

40 que al dulce puerto le lleva.

Fin.

Laus Deo. ${ }^{\mathrm{a} 4 \mathrm{v}}$

83. sulcando: surcando. 


\section{Notas textuales}

\section{Título}

lín. 1: tempestad, huracanes y temblores] tempestad y hvracanes, y temblores $S n$ [Sigo la lección de $S$, en donde la conjunción $y$ precede únicamente al último elemento de la enumeración compleja]

lín. 2: en esta ciudad] en la ciudad $S$

lín. 2: del señor] de señor $S$

lín. 3: Brizuela Corcuera] Briçuela Corçuera $S$

lín. 4: Calatrava] Calatraba $S n$ // Calatraua $S$

lín. 6: autor] auctor $S n / /$ author $S$

\section{Composición $10^{a}$}

5: Filipo] Philippo $S$

8: sujetan] subjetan $S$

13: donde] Adonde $S$ [Mantengo la lección de $S n$ por paralelismo léxico con los vv. 5 y 9 , aunque, en realidad, se debería aceptar la lección de $S$ para ajustar la medida del verso]

15: y campean y florecen] y florecen y campean $S n$ [Sigo la lección de $S$ con el fin de evitar tres asonancias consecutivas en $e$ - $a$ en los vv. 14-16)

19: común] conmun $S$

27: suceso] successo $S n$ // sucesso $S$

31: e ingenio] y ingenio $S n$ [Sigo la lección de $S$ ]

33: efecto] effecto $S$

35: del cielo llamo] del Cielo, y llamo $S n$ [Corrijo con ayuda de $S$ ]

40: velas] belas $S n$ // velas $S$

51: en el silencio] y en el silencio $S$

64: que el] quel $S$

68: dexar] dexa $S$

72: y no muevan] y mueuan $S$

73: tejas de los tejados] texas de los texados $S n / /$ tejas de los tejados $S$

75: hazen] hazian $S$

76: los cóncavos y las cuevas] los concabos y las cuebas $S n / /$ los concauos y las cueuas $S$ 80: caen] cayn $S n$ [Aunque es de suponer que el autor entonaría con diptongo [ái], sigo la lección de $S$ porque la sinéresis ajustaría la medida del verso]

88: e iglesias] y iglesias $S n$ [Sigo la lección de $S$ ]

91: del viento] de viento $S$

93: Vírgenes] virgines $S$

99: san Francisco] S. Francisco $S$

101: Leandro] Leonardo $S$

102: caen en suelo las zoteas] cayn en suelo las coteas $S n$ [Sigo la lección de $S$ : caen en suelo las çoteas (vid. v. 80)]

114: fuera] à fuera $S$

130: apriesa] apriessa $S n / /$ à priessa $S$

131: apriesa] apriessa $S n / /$ à priessa $S$ 
136: sucedió] succedio $S$

139: jarcias] Xarcias $S$

149: barcas] varcas $S n / /$ barcas $S$

150: las áncoras se les quiebran] las anchoras se le quiebran $S$

151: y van] yuan $S$

152: caballo] cauallo $S$

153: Vuelan en el Altozano] Buelan en el Altoçano Sn // Buelan en el Altozano $S$

154: bancos] vancos $S n$ // bancos $S$

156: freideras] freideras $S n / /$ freyderas $S$

159: de cuajo] de quaxo $S n / /$ de quajo $S$

161: cruces] Cruzes $S$

166: pasajera] pasagera $S n / /$ passagera $S$

175: se afirmara] lo affirmaran $S$

178: Avellaneda] Abellaneda $S n / /$ Auellaneda $S$

184: della] de ella $S$

187: oficiales] officiales $S$

190: al punto] al puncto $S$

204: rejas] rexas $S$

206: se cuentan] se cuenta $S n$ [Corrijo con ayuda de $S$ ]

210: santas] sanctas $S$

216: doncellas] donzellas $S$

228: cosa fiera] cosa horrenda $S$

230: destas] de estas $S$

240: y no mire sus ofensas] y de sus grandes ofensas $S n$ [Sigo la lección de $S:$ y no mire sus offensas]

243: pecados] peccados $S$

244: se encierran] se encierra $S n$ [Corrijo con ayuda de $S$ ]

246: della] de ella $S$

248: della] de ella $S$

Composición 2. ${ }^{\mathrm{a}}$

3: alturas] roturas $S n$ [Sigo la lección de $S$ ]

4: cueva] cueba $S n$ // cueua $S$

10: profeta] Propheta $S$

18: jarcia] Xarcia $S$

20: mesmo] mismo $S$

24: hinchada vela] hinchada bela $S n$ // inchada vela $S$

26: encuentra] enquentra $S n / /$ encuentra $S$

27: pasos] passos $S$

33: santo] sancto $S$

36: dulce] duce $S n$ [Corrijo con ayuda de $S$ ]

37: recebirle] recibirle $S$

39: barco] varco $S n / /$ barco $S$

40: al dulce] à dulce $S$ 


\section{Bibliografía $^{84}$}

Albardonedo Freire, Antonio José, El urbanismo de Sevilla durante el reinado de Felipe II, Sevilla, Guadalquivir Ediciones, 2002.

Alonso Franco, Eugenio et al., Los puentes sobre el Guadalquivir en Sevilla, Madrid, Colegio de Ingenieros de Caminos, Canales y Puertos, 1999.

Arana de Varflora, Fermín, Compendio histórico descriptivo de la muy noble y muy leal ciudad de Sevilla metrópoli de Andalucía, Sevilla, En la Oficina de Vázquez, Hidalgo y Compañía, 1789.

ArIÑo, Francisco de, Sucesos de Sevilla de 1592 a 1604, Sevilla, Imprenta de R. Tarascó y Lassa, 1873.

Cabrera de Córdoba, Luis, Relaciones de las cosas sucedidas en la Corte de España, desde 1599 hasta 1614, Madrid, Imp. de J. Martín Alegría, 1857.

Carmona, Juan Ignacio, Crónica urbana del malvivir (S. XIV-XVII). Insalubridad, desamparo y hambre en Sevilla, Sevilla, Secretariado de Publicaciones de la Universidad de Sevilla, 2000.

Cebrián, José, Estudios sobre Juan de la Cueva, Sevilla, Secretariado de Publicaciones de la Universidad de Sevilla, 1991.

Deleito y Piñuela, José, La mala vida en la España de Felipe IV, Pról. de G. Marañón, Madrid, Espasa-Calpe, 1959.

Delgado Casado, Juan, Diccionario de impresores españoles (Siglos XV-XVII), Madrid, Arco/Libros, 1996, 2 vols. (Instrumenta Bibliologica).

Ettinghausen, Henry, How the Press Began. The Pre-Periodical Printed News in Early Modern Europe, en Janus [en línea], Anexo 3 (2015), disponible en $<$ http://www.janusdigital.es/anexo.htm?id=7>.

García y García, Mariano, "Andrés Juan Gaitán de Tordesillas, Inquisidor (1571-1651)», Gaceta Cultural del Ateneo de Valladolid, 84 (2018), 35-38.

Gestoso y Pérez, José, Sevilla monumental y artística. Historia y descripción de todos los edificios notables, religiosos y civiles que existen actualmente en esta ciudad, y noticia de las preciosidades artísticas y arqueológicas que en ellos se conservan, Sevilla, Obra publicada a expensas del Ayuntamiento de Sevilla, 1889-1892, 3 vols.

González de Caldas, Victoria, "Arriadas en Sevilla: Triana y el castillo de la Inquisición (siglo XvII)», en Diego Carrasco (coord.), El río, el bajo Guadalquivir, Sevilla, Equipo 28, 1985, 54-60.

Gonzalo García, Rosario Consuelo, «Sucesos extraordinarios en torno a infieles y cristianos en la segunda mitad del siglo xvi: Escudero de Cobeña

84. Esta bibliografía contiene, en primer lugar, las referencias bibliográficas de los estudios a los que remito desde el texto y las notas de contenido, y en segundo lugar, las de los repertorios, catálogos y otras fuentes de información que cito mediante su fórmula abreviada de referencia. Todas las fuentes de Internet que aparecen citadas se han consultado en abril de 2019. 
y el registro bibliográfico de la memoria popular», en Sagrario López Poza (ed.), Las noticias en los siglos de la imprenta manual, A Coruña, SIELAE y Sociedad de Cultura Valle Inclán, 2006, 85-106.

-, La biblioteca del relacionero: Repertorios, catálogos y otras fuentes de información para la localización de las Relaciones de Sucesos (BIRESU), A Coruña, SIELAE y Sociedad de Cultura Valle Inclán, 2010.

HaZaÑas y La RÚa, Joaquín, Noticia de las academias literarias, artísticas y cientificas de los siglos XVII y XVIII, Sevilla, Oficina de D. Carlos de Torres y Daza, 1888.

Laviana Cuetos, María Luisa, «La organización de la Carrera de Indias, o la obsesión del monopolio", El comercio maritimo ultramarino. Cuadernos Monográficos del Instituto de Historia y Cultura Naval, 52 (2006), 19-35.

Maarten van Heemskerck, en Wikipedia [en línea], 14 agosto 2017, disponible en $<$ https://es.wikipedia.org/wiki/Martin_van_Heemskerck>.

Martínez de Aguirre, Javier, "Notas sobre las empresas constructivas y artísticas del Concejo de Sevilla en la Baja Edad Media, 1370-1430 (y II)", Laboratorio de Arte, 4 (1991), 11-28.

Matute y Gaviria, Justino, Hijos de Sevilla señalados en santidad, letras, armas, artes o dignidad, Con notas y correcciones, Sevilla, Oficina de El Orden, 1886-1887, 2 vols.

Morales Padrón, Francisco, La ciudad del quinientos, Sevilla, Universidad de Sevilla, 1977.

—, Memorias de Sevilla (1600-1678), Córdoba, Publicaciones del Monte de Piedad y Caja de Ahorros de Córdoba, 1981.

Morgado, Alonso, Historia de Sevilla en la qual se contienen sus antigüedades, grandezas y cosas memorables en ella acontecidas, desde su fundación hasta nuestros tiempos, Sevilla, En la imprenta de Andrea Pescioni y Juan de León, 1587.

Navarrete y Ribera, Francisco de, La Casa del juego, Madrid, Por Gregorio Rodríguez, a costa de Roberto Lorenzo, mercader de libros, véndese en su casa, en la Carrera de san Gerónimo, 1644.

Nider, Valentina y Pena Sueiro, Nieves (eds.), Malas noticias y noticias falsas. Estudio y edición de relaciones de sucesos (siglos XVI-XVII), Trento, Università degli Studi di Trento, 2019 (Labirinti).

Ortiz de ZúNíga, Diego, Annales eclesiásticos y seculares de la muy noble y muy leal ciudad de Sevilla, metrópoli de la Andaluzía, que contienen sus más principales memorias desde el año de 1246 [...] hasta el de 1671 [...], Madrid, En la Imprenta Real, 1677.

Penney, Clara Louisa, Printed Books (1468-1700) in the Hispanic Society of America, New York, The Hispanic Society of America, 1965.

Peña Díaz, Manuel, «El río como amenaza», en José Peral López (coord.), Guadalquivir. Mapas y relatos de un río. Imagen y mirada, Sevilla, Editorial de la Universidad de Sevilla, 2017, 47-61.

Pérez Aguilar, Francisco, El puente de barcas de Sevilla (1171-1852) y otros puentes de barcas de las provincias de Sevilla y Cádiz, Sevilla, Kronos Ediciones, 2013. 
Ponz, Antonio, Viage de España, en que se da noticia de las cosas más apreciables y dignas de saberse que hay en ella, Madrid, Por la viuda de Joaquín Ibarra, 1791, Tomo XVI: Trata de Andalucía.

Rodríguez Marín, Francisco, Obras de Pedro Espinosa, Madrid, Tip. de la Revista de Archivos, 1909.

Tirado de Aldana, Francisco José, Antigüedad del sagrado templo de Nuestro Señor San Salvador en Sevilla [Manuscrito], 1726, signatura Mss. 23130(1), disponible en <http://bdh.bne.es/bnesearch/detalle/bdh0000050371>.

Vélez de Guevara, Luis, El Diablo Coivelo, novela de la otra vida, traduzida a esta por..., Madrid, Imprenta del Reyno, 1641. (Hay ed. con pról. y notas de Francisco Rodríguez Marín: Madrid, La Lectura, 1918).

\section{Fórmulas abreviadas de referencia}

Agulló. Relaciones de sucesos, I = Agulló y Cobo, Mercedes, Relaciones de sucesos I: Años 1477-1619, Madrid, CSIC, 1966 (Cuadernos Bibliográficos, XX).

Aut. $=$ Real Academia Española, Diccionario de Autoridades, 1726-1737, Ed. facsímil, Madrid, Editorial Gredos, 1990, 3 vols.

CBDRS = Universidade da Coruña, Grupo de INVESTigación SIELAE, $C a-$ tálogo y biblioteca digital de relaciones de sucesos, BIDISO (Biblioteca Digital Siglo de Oro) [en línea], disponible en <http://www.bidiso.es/CBDRS>.

CCPBE = Ministerio de Cultura, Dirección General del Libro, Archivos y Bibliotecas, Catálogo colectivo del patrimonio bibliográfico español [en línea], disponible en <http://catalogos.mecd.es/CCPB/ccpbopac/>.

CORDE = Real ACAdemia Española, Banco de datos (CORDE), Corpus diacrónico del español [en línea], disponible en <http://corpus.rae.es/cordenet.html>. $D B E=$ SÁnchez Martín, Juan Luis, «Bernardino de Avellaneda y Leiva», en Diccionario biográfico español, Madrid, Real Academia de la Historia, 2010, vol. VI, disponible en <http://dbe.rah.es/biografias/20907/bernardino-deavellaneda-y-leiva>.

$D L E=$ Real Academia Española, Diccionario de la lengua española, 23. a ed., Madrid, Espasa Calpe, 2014, disponible en <http://dle.rae.es/>.

Domínguez Guzmán. Imprenta en Sevilla = Domínguez Guzmán, Aurora, La imprenta en Sevilla en el siglo XVII (Catálogo y análisis de su producción), 1601-1650, Sevilla, Secretariado de Publicaciones de la Universidad de Sevilla, 1992.

Escudero = Escudero y Perosso, Francisco, Tipografía hispalense. Anales bibliográficos de la ciudad de Sevilla desde el establecimiento de la imprenta hasta fines del siglo XVIII, Madrid, Sucesores de Rivadeneyra, 1894.

Gallardo. Ensayo = Gallardo, Bartolomé José, Ensayo de una biblioteca española de libros raros y curiosos, formada con los apuntamientos de don B. J. Gallardo, coordinados y aumentados por M. R. Zarco del Valle y J. Sancho Rayón, Madrid, Imp. y Estereotipia de M. Rivadeneyra, 1863-1889. 4 vols. 
Gonzalo García. El legado bibliográfico del duque de T'Serclaes = GonZalo García, Rosario Consuelo, El legado bibliográfico de Juan Pérez de Guzmán y Boza, duque de T'Serclaes de Tilly: Aportaciones a un catálogo descriptivo de relaciones de sucesos (1501-1625), Madrid, Arco/Libros, 2018 (Tipobibliografía Española).

Hazañas. Sevilla = Hazañas y La Rúa, Joaquín, La imprenta en Sevilla. Ensayo de una historia de la tipografía sevillana y noticias de algunos de sus impresores desde la introducción del arte tipográfico en esta ciudad hasta el año de 1800, Sevilla, Imp. de la Revista de Tribunales, 1892.

Huth. Catalogue 1880 = The Huth Library. A Catalogue of the Printed Books, Manuscripts, Autograph Letters, and Engravings Collected by Henry Huth, with Collations and Bibliographical Descriptions, London, Ellis and White, 1880, 5 vols.

Hutн. Catalogue 1911-1920 = Huth, Henry, Catalogue of the Famous Library of Printed Books, Illuminated Manuscripts, Autograph Letters and Engravings. Collected by Henry Huth, and since Maintained and Augmented by his Son Alfred H. Huth, London, Dryden Press: J. Davy \& Sons, 1911-1920, 9 vols.

LASSO de LA Vega = LASSO de la Vega y ARgüELLes, Ángel, Historia y juicio critico de la escuela poética sevillana en los siglos XVI y XVII, precedida de una carta de J. Amador de los Ríos, Madrid, Imprenta de la viuda e hijos de Galiano, 1871.

Maffei y Rúa Figueroa = Maffei, Eugenio, y Rúa Figueroa, Ramón, Apuntes para una biblioteca española de libros, folletos y artículos, impresos y manuscritos, relativos al conocimiento y explotación de las riquezas minerales y a las ciencias auxiliares. Acompañados de reseñas biográficas y de un ligero resumen de la mayor parte de las obras que se citan, Madrid, Imprenta de J. M. Lapuente, 1872-1873, 2 vols.

Mendoza Díaz-Maroto. Catálogo. Suplemento $I I=$ Mendoza Díaz-MaroTO, Francisco, «Catálogo del fondo antiguo de una biblioteca de Albacete. Suplemento II», Al-Basit. Revista de Estudios Albacetenses, 3. a época, XXXI (2006), 50, 333-395.

Palau $=$ Palau y Dulcet, Antonio, Manual del librero hispano-americano. Bibliografía general española e hispanoamericana desde la invención de la imprenta hasta nuestros tiempos con el valor comercial de los impresos descritos, 2. a ed. corr. y aum., Barcelona, etc., Librería Anticuaria de A. Palau, etc., 1948-1977, 28 vols.

Palomo. Riadas del Guadalquivir = Palomo, Francisco de Borja, Historia crítica de las riadas o grandes avenidas del Guadalquivir en Sevilla, desde su reconquista hasta nuestros días, Sevilla, F. Álvarez y C. a , 1878, 2 vols.

Rodríguez Marín. Pedro Espinosa = Rodríguez Marín, Francisco, Pedro Espinosa: Estudio biográfico, bibliográfico y crítico, Madrid, Tip. de la Revista de Archivos, 1907.

Rodríguez Moñino. Marqués de Jerez = Catálogo de la Biblioteca del Marqués de Jerez de los Caballeros, Reimpreso por primera vez en facsímile, precedido 
de una biografía del gran bibliófilo por Antonio Rodríguez-Moñino, Madrid, Librería para Bibliófilos, 1966.

Serrano Ortega. Bib. catedral Sevilla $=$ Serrano y Ortega, Manuel, Bibliografía de la catedral de Sevilla, Sevilla, Escuela Tipográfica y Librería Salesianas, 1901.

Simón Díaz. BLH = Simón DíAz, José, Bibliografía de la Literatura Hispánica, Madrid, CSIC, 1950-1993, 16 vols.

Simón DíAz. Libros a buscar = Simón DíAz, José, «Libros a buscar: I. Impresos castellanos de los siglos XVI y XVII», Cuadernos Bibliográficos, XXX (1973), 285-319.

Simón DíAz. Relaciones (1540-1650) = Simón DíAz, José, «Algunas relaciones de sucesos de los años 1540-1650», Bibliotheca Hispana, XV (1957), 4, 506-523. 